\title{
BMJ
}

\section{The global impact of income inequality on health by age: an observational study}

\author{
Danny Dorling, professor of human geography, ${ }^{1}$ Richard Mitchell, reader in health inequalities, ${ }^{2}$ \\ Jamie Pearce, co-director ${ }^{3}$
}

'Department of Geography, University of Sheffield,

Sheffield S10 2TN

${ }^{2}$ Public Health and Health Policy, University of Glasgow,

Glasgow G12 8RZ

${ }^{3}$ GeoHealth Laboratory, Department of Geography, University of Canterbury, Private Bag 4800, Christchurch 8020, New Zealand

Correspondence to: D Dorling Daniel.dorling@sheffield.ac.uk

doi:10.1136/bmj.39349.507315.DE

\section{ABSTRACT}

Objectives To explore whether the apparent impact of income inequality on health, which has been shown for wealthier nations, is replicated worldwide, and whether the impact varies by age.

Design Observational study.

Setting 126 countries of the world for which complete data on income inequality and mortality by age and sex were available around the year 2002 (including $94.4 \%$ of world human population).

Data sources Data on mortality were from the World Health Organization and income data were taken from the annual reports of the United Nations Development Programme.

Main outcome measures Mortality in 5-year age bands for each sex by income inequality and income level.

Results At ages 15-25 and 29-39 variations in income inequality seem more closely correlated with mortality worldwide than do variations in material wealth. This relation is especially strong among the poorest countries in Africa. Mortality is higher for a given level of overall income in more unequal nations.

Conclusions Income inequality seems to have an influence worldwide, especially for younger adults. Social inequality seems to have a universal negative impact on health. Humans are social animals and are not well constructed physiologically to survive in uncooperative surroundings-particularly during the prime of life.

\section{INTRODUCTION}

Many studies of the potential impact of inequalities in income on health outcomes have been undertaken in recent years. ${ }^{1-14}$ Some have claimed that the apparent association between greater income inequality in a nation with higher mortality may be an artefact, ${ }^{15}$ but the weight of recent evidence has pointed towards it being a real effect. ${ }^{6}$ In rich nations, the most prominent hypothesis is that the psychosocial stress of being in a relatively low position within a social and economic hierarchy leads to physiological harm. ${ }^{16}$

Most studies of this relation have focused on wealthier nations. In such nations, being among the poorest in society is usually no longer a situation adverse enough to threaten life directly through mechanisms such as malnutrition, poor sanitation, and poor shelter-as is often the case in poorer nations of the world. However, it has recently been suggested that the effect of social inequalities on health is important worldwide, not just in affluent nations. ${ }^{6}$

If psychosocial stress is a key mechanism by which inequality is damaging to population health in affluent nations, we should expect the impact of inequality to vary over the life course. ${ }^{17}$ This is because how we are viewed by our peers is thought to matter more at some ages than others. However, international studies of the effects of income inequality on mortality across the life course are rare. A study of 22 countries in the third wave of the Luxembourg income study (1989-92) found that the effect of income inequality was strong among infants but decreased with age and reversed for those older than $65 .{ }^{5}$ Similarly, a study of 13 countries in the Organisation for Economic Cooperation and Development (OECD), using data from the 1970s to the early $1990 \mathrm{~s}$, found that the association between income inequality and mortality weakened after the age of $25 .^{11}$

The age-specific relation between income inequality and mortality is well studied in the United States. The weight of evidence suggests that income inequality is a significant predictor of mortality among infants, ${ }^{238121418}$ but this relation is weaker ${ }^{2-14}$ or disappears ${ }^{101218}$ among people older than about 65 . In all age-specific studies, income inequality exerted the greatest influence on mortality at some point between the ages of 15 and 64 years. Thus, inequalities seem to be most damaging to health during working adult ages.

In this study we have explicitly examined variation by age in the relation between income inequality and mortality and, more importantly, have extended such analyses to countries not included in previous studies. This has been made possible through the use of recently released (and independently validated) secondary data which cover nations other than the richest that are members of the OECD. Thus, not only can we explore variation in the relation between income inequality and mortality by age, we can explore it in a truly global dataset.

\section{METHODS AND DATA}

We report results based on 126 countries for which complete data on income inequality and mortality by 
age and sex were available around the year 2002, and which include $94.4 \%$ of the world's population. We obtained the mortality data from the World Health Organization. ${ }^{19}$ These data enable us to calculate mortality by age group ( $<1$ year, $1-4,5-9$, and 5 year bands up to 95-99) and sex (see table for details). We used a consistent measure of wealth that is well known and available for most countries in the world - the log of gross domestic product (GDP) per capita adjusted to

Summary statistics for annual mortality per 100000 people worldwide by age and sex

\begin{tabular}{|c|c|c|}
\hline \multirow[b]{2}{*}{ Sex and age (years) } & \multicolumn{2}{|c|}{ Mortality per 100000 people } \\
\hline & Mean & Median (range) \\
\hline \multicolumn{3}{|l|}{ Males } \\
\hline$<1$ & 5608 & 3147 (304-30 093) \\
\hline $1-4$ & 446 & $187(12-2819)$ \\
\hline $5-9$ & 126 & $60(7-798)$ \\
\hline $10-14$ & 82 & $58(11-368)$ \\
\hline $15-19$ & 150 & $131(29-465)$ \\
\hline $20-24$ & 309 & $220(67-1281)$ \\
\hline $25-29$ & 491 & $241(58-3098)$ \\
\hline $30-34$ & 703 & 304 (71-5229) \\
\hline $35-39$ & 824 & $395(95-5723)$ \\
\hline 40-44 & 947 & $541(148-5545)$ \\
\hline $45-49$ & 1141 & $787(236-5150)$ \\
\hline $50-54$ & 1407 & $1153(375-4507)$ \\
\hline $55-59$ & 1865 & $1740(613-3865)$ \\
\hline $60-64$ & 2648 & $2653(1023-4780)$ \\
\hline $65-69$ & 3908 & 4018 (1759-6553) \\
\hline $70-74$ & 5890 & $5942(2839-9828)$ \\
\hline $75-79$ & 8835 & 9000 (4524-13 322) \\
\hline $80-84$ & 13632 & 13757 (7624-22 229) \\
\hline $85-89$ & 20448 & 21269 (11 580-34 015) \\
\hline $90-94$ & 29702 & $30948(16875-47586)$ \\
\hline $95-99$ & 41839 & $43264(24675-60000)$ \\
\hline \multicolumn{3}{|l|}{ Females } \\
\hline$<1$ & 4759 & $2575(246-23775)$ \\
\hline $1-4$ & 475 & $168(10-3201)$ \\
\hline $5-9$ & 120 & $50(4-831)$ \\
\hline $10-14$ & 79 & $39(8-496)$ \\
\hline $15-19$ & 167 & $65(16-872)$ \\
\hline $20-24$ & 337 & $87(22-2615)$ \\
\hline $25-29$ & 516 & $106(24-4753)$ \\
\hline $30-34$ & 626 & $129(26-5966)$ \\
\hline $35-39$ & 607 & $186(60-5059)$ \\
\hline $40-44$ & 615 & $277(90-4170)$ \\
\hline $45-49$ & 659 & $426(144-3117)$ \\
\hline $50-54$ & 826 & $632(221-2729)$ \\
\hline $55-59$ & 1134 & $928(306-2712)$ \\
\hline $60-64$ & 1625 & $1491(460-3213)$ \\
\hline $65-69$ & 2580 & $2371(745-4860)$ \\
\hline $70-74$ & 4160 & 4026 (1234-7665) \\
\hline $75-79$ & 6677 & $6643(2248-10670)$ \\
\hline $80-84$ & 10856 & $11369(4307-15644)$ \\
\hline $85-89$ & 17138 & $18112(7986-25757)$ \\
\hline $90-94$ & 26076 & 27680 (13 722-41 719) \\
\hline $95-99$ & 38176 & $40043(21620-58$ 196) \\
\hline
\end{tabular}

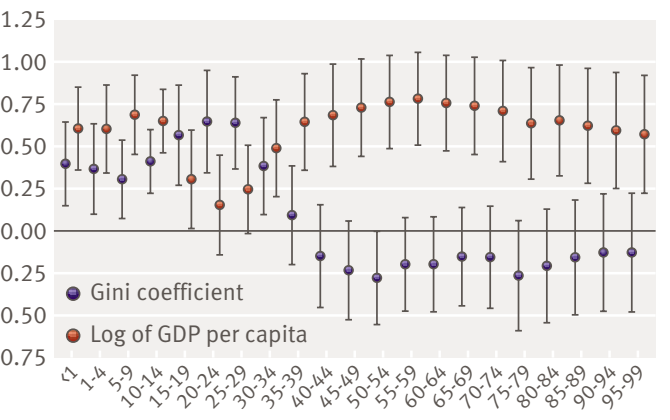

Age (years)

Fig 1 Association of income inequality and affluence with mortality in the 30 countries of the OECD (income inequality measured as the Gini coefficient, and affluence as the log of gross domestic product (GDP) per capita adjusted to ensure purchasing power parity)

ensure purchasing power parity. ${ }^{20}$ We also used a widely published measure of inequality from the same United Nations Development Programme source - the Gini coefficient. ${ }^{20}$ The mean and median (range) values for these two measures respectively are $\$ 9348$ and $\$ 4955$ (\$521-\$68000), and 40.1 and 38.0 (24.4-70.7).

We treated whole countries as units in a natural experiment. This approach assumes that the nation state is the level at which the effects of material wealth and income inequality should be most apparent. The nation state is arguably the key unit of social, political, and economic systems which produce both wealth and inequality. ${ }^{7}$ All countries were thus weighted equally in the results shown here. Results of analyses in which countries were weighted by population (not shown) did not differ greatly.

\section{Statistical analysis}

We modelled the extent to which relations between health and income, and between health and income inequality seemed to vary across each of the age

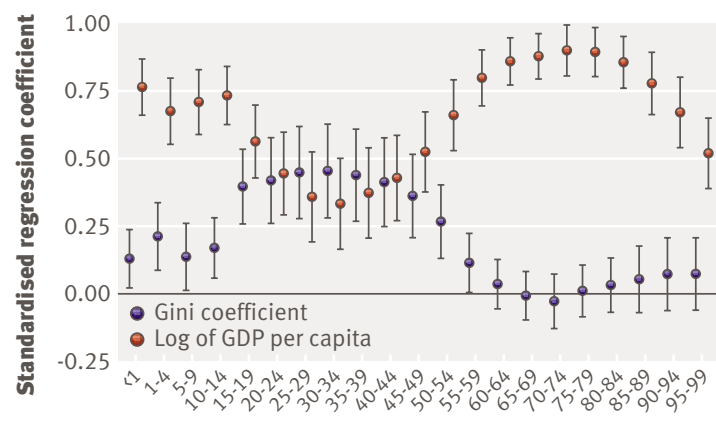

Age (years)

Fig 2 Association of income inequality and affluence with mortality in all countries worldwide (income inequality measured as the Gini coefficient, and affluence as the log of gross domestic product (GDP) per capita adjusted to ensure purchasing power parity) 


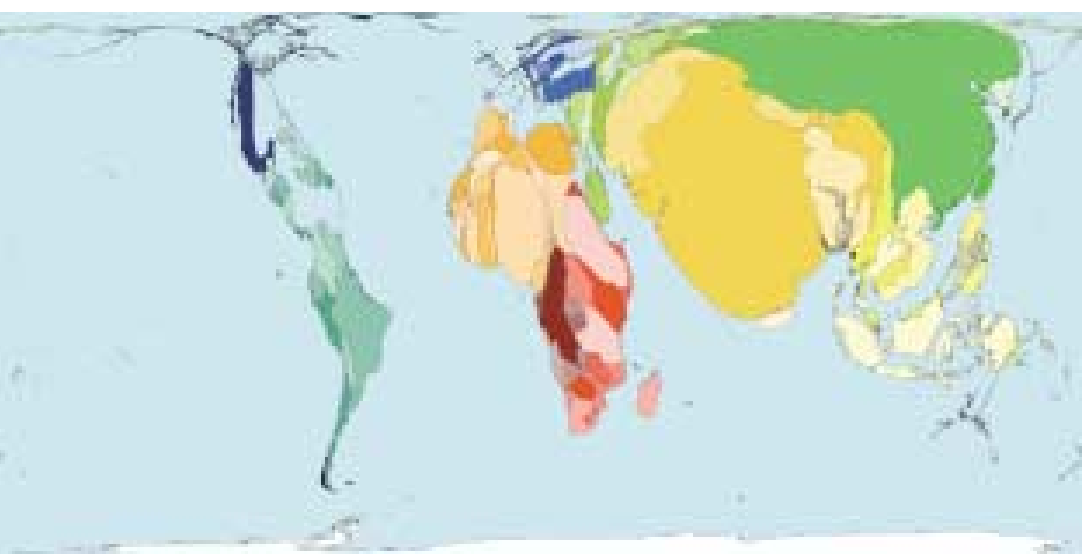

The world's countries shaped with area in proportion to the number of people living on $\leq \$ 10$ a day (from Worldmapper, www.worldmapper.org/display.php?selected=153). Some 3.5 billion people, more than half the world population, survive on the equivalent, or less, of what $\$ 10$ in the US would buy a day

bands. We used linear regression to measure the association between mortality as the dependent variable and log of adjusted gross domestic product per capita as the independent predictor. We took a similar approach for the Gini coefficient.

We compared the predictive power of each of the independent variables by means of standardised $\beta$ coefficients for each variable, derived from each separate age-group model. These regression coefficients are those obtained by first standardising all variables to have a mean of 0 and a standard deviation of 1 . We used Stata v9.2 to run the models. We also performed a two tailed test with $\alpha$ of 0.05 of the hypothesis that the coefficients varied with age.

\section{Sensitivity analyses}

Many facets of modelling can have a significant effect on the outcome - such as the weighting used, the countries included, dates to which data refer, whether to control for other aspects of the nature of societies; whether to treat all national societies as separate entities; and the source of inequality measure used. We

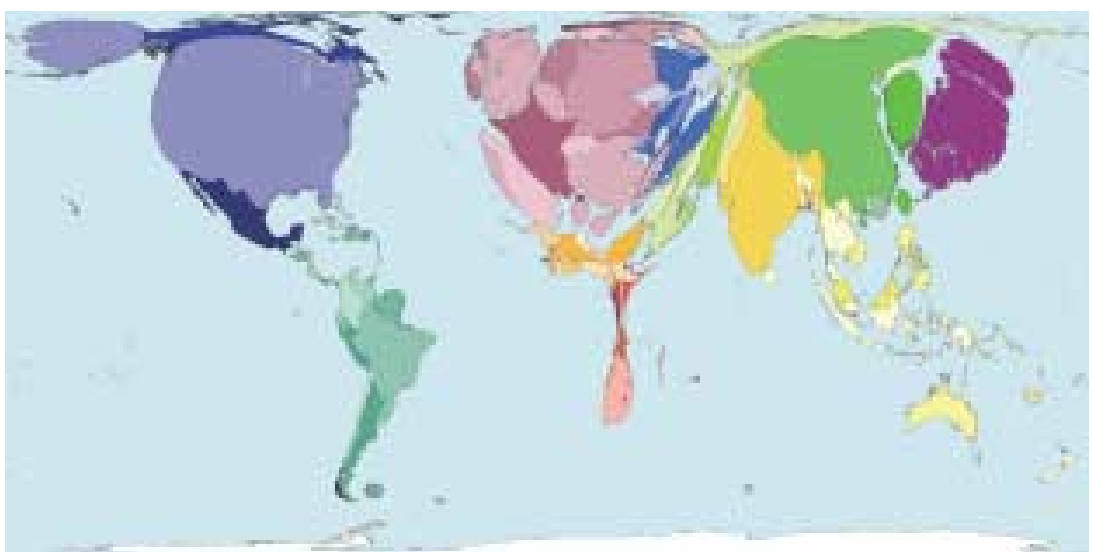

The world's countries shaped with area in proportion to the gross domestic product per capita of people adjusted for purchasing power parity (2002 data) (from Worldmapper, www.

worldmapper.org/display.php?selected=170). Roughly $\$ 50$ trillion is "earned" a year worldwide, $\$ 7800$ per person, or $\$ 21$ on average a day therefore undertook extensive sensitivity analyses, and ran models to include an extra 70 or so countries without complete data, using estimates to fill the gaps. These countries tend to have small populations and contain only about $5 \%$ of the world population. We also tested alternative measures of income inequality ${ }^{21}$ weighting each country for population size, and examined each continent independently.

\section{RESULTS}

Figures 1 and 2 show the strength of the relation between each variable and age-specific mortality for both sexes combined (a larger coefficient indicates a stronger relation). A statistical test that the coefficients varied with age suggested that the correlation with the standardised Gini coefficient was $-0.559(\mathrm{P}<0.01)$, but the relation between age and log of income coefficients was not significant $(0.334, \mathrm{P}>0.05)$. We find that income inequality had the greatest influence on mortality between the ages of 15 and 29 in OECD countries (fig 1), and between the ages of 25 and 39 worldwide (fig 2). The strength of the worldwide relation was reduced when we omitted countries in Africa (results not shown). The worldwide result is thus partly a product of processes operating most strongly in this continent, not simply a reflection of those operating within OECD countries.

The figures suggest that the strength of the association of inequality with mortality varies inversely with that for the association of affluence with mortalitythat is, as inequality reaches its maximum influence, affluence reaches its minimum. This is a new finding which may have important implications for debates on the likely causal mechanisms.

\section{Secondary analyses}

We obtained similar results when we studied the two sexes separately (results not shown). Inequality seemed to matter slightly more for males than females, but the shape and nature of the associations with age were not fundamentally altered. Similarly, the factors included in our sensitivity analyses had little impact on the results. A further concern that we were not able to address was the effect of using only nation-state data. If it were possible to use data on subdivisions of India and China, say, rather than treating those countries as two homogeneous observations, that might well be worth while.

\section{DISCUSSION}

Our results prompt a series of hypotheses that we think are worth further investigation. Firstly, that the much disputed impact of income inequality on health is real, but that, because the impact varies with age, studies that have not accounted for this can show wide variation in association of inequality with population health. Future studies should consider outcomes for different age groups.

Secondly, there is an age related mechanism that results in higher mortality being experienced in societies where there is greater social competition, all else 


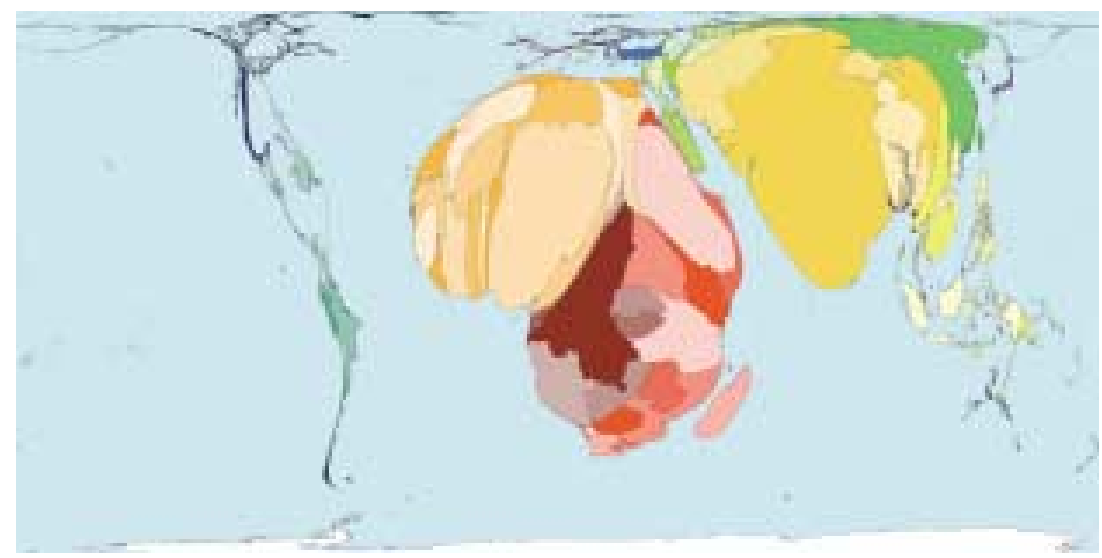

The world's countries shaped with area in proportion to the deaths of children aged 1-4 years inclusive (2002 data) (from Worldmapper, www.worldmapper.org/display.php?selected=263). Some 3.2 million children of these ages die every year

being equal. Higher rates of income inequality tend to reflect more competitive rather than more cooperative societies. Whatever the mechanism that results in harm from competition (or protection from cooperation), it has its strongest effects in early to middle adulthood.

Thirdly, in the nations with the lowest child and infant mortality, the importance of income inequalities will often be most obvious. This might be why the influence of income inequalities has been found most strongly in studies of all age mortality in OECD countries.

Fourth, given the importance of African countries in providing evidence of a relation between inequality and mortality worldwide, high mortality from AIDS, armed conflict, and other causes common in more unequal and very poor countries might be a factor in explaining the observed relation.

Lastly, social inequalities as reflected through unequal incomes are damaging to health for those living in both rich and poor nations, and the direct mechanisms for such damage are likely to vary by area. Psychosocial stress is unlikely to be the only route by which income inequality damages health. However, the underlying mechanism may be similar -that, because humans are social animals, human health is best protected when people cooperate.

Our finding that, as inequality reaches its maximum influence on mortality, affluence reaches its minimum influence may have important implications for debates on the likely causal mechanisms. Although some hypotheses are consistent with this finding, others would predict the opposite. It may well be the case, for example, that greater equality mitigates the need for greater affluence to be present for health to improve (as reflected in lower mortality).

\section{Future research}

More detailed studies are needed to consider mortality and psychological morbidity by age and sex in relation to social inequalities between people. Furthermore, time trends should be studied where possible. Do changes in mortality and morbidity over time correlate well at particular ages with increases or decreases in social (reflected by income) inequality for particular age cohorts and not for others? Patterns in the prevalence of mortality by cause, age, and sex should be studied to infer the possible biological processes at play and the extent to which external injuries and accidents are particularly important. Lastly, the possible protective effects of old age and of young age (if not actual infancy) need to be further studied to ascertain why no strong relation is observed between income inequalities and mortality at these ages.

It has been argued that estimates of the potential impact on mortality of a narrowing of inequalities are useful in promoting policies to preserve life. This has been attempted in countries where a great deal of detailed evidence has been amassed. ${ }^{22}$ Such data are not available worldwide. Our exploratory analysis found that the simplest of models suggest that, at the most affected ages, up to a quarter of deaths might be avoided were the most unequal of countries to become more equal. However, such simple models may well overestimate or underestimate the benefits of improved equality in the complexity of the real world.

\section{Conclusion}

Income inequality is associated with higher mortality levels in all nations worldwide, not just affluent ones, but the effects are more pronounced at different ages. Although the direct mechanisms that operate are likely to be different between different countries, there does not seem to be a beneficial impact of social inequality on health anywhere.

We thank colleagues, two referees, a statistical referee, and the editorial committee for many useful points made in reference to an earlier version of this paper. We are solely responsible for the views presented here.

Contributors: All authors contributed to devising, writing, and revising this manuscript. DD collected and checked the initial data used, RM undertook the analysis, and JP conducted the initial literature review. DD is guarantor. Funding: RM was funded by the Chief Scientist's Office of the Scottish Executive. DD was supported by a British Academy Research Leave Fellowship while this paper was being written. The opinions are of those of the authors. Competing interests: All authors are in their 30s and are currently seeking the "bubble reputation" (As You Like It 2.7.139-65). However, all have their feet on the ground, having trained in medical geography.

1 Hales S, Howden-Chapman P, Salmond C, Woodward A, Mackenbach J. National infant mortality rates in relation to gross national product and distribution of income. Lancet 1999;354:2047.

2 Kaplan GA, Pamuk ER, Lynch JW, Cohen RD, Balfour JL. Inequality in income and mortality in the United States: analysis of mortality and potential pathways. BMJ 1996;312:999-1003.

3 Lobmayer P, Wilkinson RG. Inequality, residential segregation by income, and mortality in US cities. / Epidemiol Community Health 2002;56:183-7.

4 Lynch J, Smith GD, Harper S, Hillemeier M. Is income inequality a determinant of population health? Part 2. US National and regional trends in income inequality and age- and cause-specific mortality. Milbank Q 2004;82:355-400.

5 Lynch J, Smith GD, Hillemeier M, Shaw M, Raghunathan T, Kaplan G. Income inequality, the psychosocial environment, and health: comparisons of wealthy nations. Lancet 2001;358:194-200.

6 Ram R. Further examination of the cross-country association between income inequality and population health. Soc Sci Med 2006;62:779-91.

7 Wilkinson RG, Pickett KE. Income inequality and population health: a review and explanation of the evidence. Soc Sci Med 2006;62:1768-84 


\section{WHAT IS ALREADY KNOWN ON THIS SUBJECT}

Mortality falls as incomes rise, and this relation holds both between and within countries

Among affluent nations, this relation is tempered as income inequalities increase: the health gains from increases in income are less in more unequal nations

There is some evidence that these effects are more pronounced at different ages

\section{WHAT THIS STUDY ADDS}

High inequalities in income are closely associated with higher mortality in both poor and rich nations of the world

This is particularly apparent when the effects are studied by age: worldwide, income inequality is most strongly detrimental to health in young adulthood

8 Brodish $\mathrm{PH}$, Massing $\mathrm{M}$, Tyroler $\mathrm{HA}$. Income inequality and all-cause mortality in the 100 counties of North Carolina. South Med J 2000;93:386-91.

9 Chiang T. Economic transition and changing relation between income inequality and mortality in Taiwan: regression analysis. $B M$ J 1999;319:1162-5.

10 Daly MC, Duncan GJ, Kaplan GA, Lynch JW. Macro-to-micro links in the relation between income inequality and mortality. Milbank $Q$ 1998; 76: 303-4, 315-39.

11 Mclsaac S, Wilkinson RG. Income distribution and cause-specific mortality. Eur J Public Health 1997;7:45-53.

12 Ross NA, Wolfson MC, Dunn JR, Berthelot JM, Kaplan GA, Lynch JW. Relation between income inequality and mortality in Canada and in the United States: cross sectional assessment using census data and vital statistics. BMJ 2000;320:898-902.

13 Weatherby N, Nam C, Isaac L. Development, inequality, health care, and mortality at the older ages: a cross-national analysis. Demography 1983;20:27-43.

14 Lynch JW, Kaplan GA, Pamuk ER, Cohen RD, Heck KE, Balfour JL, et al. Income inequality and mortality in metropolitan areas of the United States. Am J Public Health 1998;88:1074-80.

15 Wagstaff A, van Doorslaer E. Income inequality and health: what does the literature tell us? Annu Rev Public Health 2000;21:543-67.

16 Marmot MG. The status syndrome: how social standing affects our health and longevity. London: Bloomsbury, 2004.

17 Davey Smith G. Health inequalities: lifecourse approaches. Bristol: Policy Press, 2003.

18 Duleep HO. Mortality and income inequality among economically developed countries. Soc Secur Bull 1995;58:34-50.

19 Lopez A, Ahmad O, Guillot M, Inoue M, Ferguson B. Life tables for 191 countries for 2000: data, methods, results. Geneva: World Health Organization, 2001. (GPE discussion paper No 40.)

20 United Nation Development Programme. Table 14 (Gini index of income inequality). In: Human development report 2004. Geneva: UNDP, 2004.

21 Babones SI. The country-level income structure of the world economy. J World Systems Res 2005;XI(1):29-58 (http://jwsr.ucr. edu/archive/vol11/number1/index.php?art3=\&).

22 Mitchell R, Dorling D, Shaw M. Inequalities in life and death: what if Britain were more equal? London: Joseph Rowntree Foundation, 2000.

Accepted: 10 August 2007 